Published in final edited form as:

J Sch Health. 2007 January ; 77(1): 41-47.

\title{
Policies and Opportunities for Physical Activity in Middle School Environments
}

\author{
Deborah R. Young, PhD ${ }^{\mathrm{a}}$, Gwen M. Felton, PhD ${ }^{\mathrm{b}}$, Mira Grieser, MHS ${ }^{\mathrm{C}}$, John P. Elder, PhD ${ }^{\mathrm{d}}$, \\ Carolyn Johnson, $\mathbf{P h D}^{\mathrm{e}}$, Jung-Sun Lee, $\mathbf{P h D}^{\mathbf{f}}$, and Martha Y. Kubik, PhDg
}

a Associate Professor, (dryoung @ umd.edu), Department of Kinesiology, University of Maryland, 2312 Health and Human Performance Building, College Park, MD 20742

b Professor, (gwen.felton@sc.edu), College of Nursing, University of South Carolina, Columbia, SC 29208

c Faculty Research Assistant, (mgrieser@umd.edu), Department of Kinesiology, University of Maryland, Welch Center East, 2809 Boston St, Suite 7, Baltimore, MD 21224

d Professor, (jelder@mail.sdsu.edu), Graduate School of Public Health, San Diego State University, 9245 Sky Park Court, Suite 221, San Diego, CA 92123

e Clinical Associate Professor, (cjohnso5@tulane.edu), Department of Community Health Sciences, Tulane University School of Public Health \& Tropical Medicine, 1440 Canal St, New Orleans, LA, 70112

f Assistant Professor, (jung-sun.lee@ mail.cscc.unc.edu), Department of Biostatistics, University of North Carolina at Chapel Hill, 137 E. Franklin St, Suite 203, Mail Station 8030, Room 11, Chapel Hill, NC 27514-4145

g Assistant Professor, (kubik002@tc.umn.edu), School of Nursing, University of Minnesota, 6-101 Weaver Densford Hall, 308 Harvard St SE, Minneapolis, MN 55455

\section{Abstract}

BACKGROUND—This study examined physical activity opportunities and barriers at 36 geographically diverse middle schools participating in the Trial of Activity for Adolescent Girls.

METHODS-Principals, physical education and health education department heads, and program leaders were interviewed to assess policies and instructional practices that support physical activity.

RESULTS-Schools provided approximately 110 hours per year in physical education instruction. Approximately $20 \%$ of students walked or bicycled to school. Eighty-three percent of schools offered interscholastic sports and 69\% offered intramural sports. Most schools offered programs for girls, but on average, only 24 girls ( $\sim 5 \%)$ in the schools attended any programs. Only $25 \%$ of schools allowed after school free play. An overall score created to assess school environmental support for physical activity indicated that, on average, schools met 6.7 items of 10 items. Free/reduced lunch program participation versus not $(\mathrm{p}=.04)$, perceived priority of physical education instruction over coaching $(\mathrm{p}=.02)$, and safety for walking/bicycling to school $(\mathrm{p}=.02)$ predicted environmental support score.

CONCLUSIONS-Schools have policies and practices that support physical activity, although unfavorable practices exist. Schools must work with community partners and officials to provide environments that optimally support physical activity, especially schools that serve low-income students.

Address correspondence to: Deborah R. Young, (dryoung@umd.edu), Department of Kinesiology, University of Maryland, 2312 Health and Human Performance Building, College Park, MD 20742. 


\section{Keywords}

middle schools; physical activity; adolescents; socioeconomic status

Overweight and obesity are multifactorial phenomena that are endemic in the United States, even among our youth. ${ }^{1}$ One major factor of influence for overweight and obesity, as well as for many other chronic diseases, is a population-wide decline in physical activity. Declines in physical activity that begin in adolescence ${ }^{2}$ have important implications for adult health. Accumulated evidence shows that overweight youth become overweight adults, ${ }^{3}$ and although the evidence is not as strong, inactive youth also become inactive adults. ${ }^{4-6}$ The importance, then, of encouraging and maintaining physical activity among children and adolescents cannot be overstated.

Inasmuch as $90 \%$ of the nation's children participate in school-based education, government agencies and others assert that schools are ideal venues for increasing opportunities for physical activity. ${ }^{7,8}$ In school environments that are favorable to physical activity, adolescents have opportunities to be active, which in turn can reduce their current and future risk for developing chronic disease.

The Centers for Disease Control and Prevention (CDC) promotes this strategy through their guidelines for healthy schools. ${ }^{9}$ These guidelines recognize opportunities for incorporating the concept of healthy living into all aspects of the school, including classroom instruction, environmental policy and supports, food service, and community and family involvement. In addition, the CDC published recommendations for schools and communities to promote physical activity among youth. ${ }^{7}$

Subsequent to the CDC recommendations, in 2000 the Secretary of Health and Human Services and the Secretary of Education issued a report to the President on strategies to promote better health for young people through physical activity and sports. ${ }^{10}$ This document lists approaches that schools can take to promote physical activity. They include (1) establishing policies that promote physical activity; (2) providing environments that encourage safe and enjoyable physical activity; (3) implementing quality, daily physical activity instruction, and curricula; (4) implementing health education that provides students with knowledge and needed behavioral skills; (5) providing sufficient training for personnel involved in physical activity instruction or promotion; and (6) providing inclusive extracurricular approaches that meet the needs and interests of all students. Information on the extent to which schools are implementing these approaches is not available, however.

Although the CDC periodically monitors school-level information on physical activity policies and programs, surveys were performed only in 1994 and 2000, ${ }^{9}$ and no data were presented at the individual school level. Tompkins et al reported on school environments for physical activity in West Virginia schools but did not aggregate information. ${ }^{11}$ Barriers or challenges exist within school systems that prevent the optimization of the school as a health-promoting facility, especially relative to physical activity. These barriers have not been fully documented at the school level.

This report describes the school climate regarding physical activity education and practice in 36 middle schools from a variety of geographical regions in the United States. Policies, programs, and opportunities available in middle schools were assessed and compared to published recommendations. Because the decline in physical activity is greater among adolescent girls than boys, ${ }^{12}$ our particular focus was on programs and opportunities available for girls. Schools participating in the Trial of Activity for Adolescent Girls (TAAG) are 
described because of the extensive data that were available and because of their diversity in demographic and geographic makeup.

\section{METHODS}

\section{Background}

TAAG is a randomized, controlled, multicenter field trial of 36 middle schools. ${ }^{13}$ Field sites located in 6 states (Arizona, California, Louisiana, Maryland, Minnesota, and South Carolina) participated in the study, along with a Coordinating Center at University of North Carolina, Chapel Hill. The study was funded by the National Heart, Lung, and Blood Institute, which actively participated in the development, implementation, and evaluation of the study. The primary specific aim was to determine if an intervention that provides physical activity opportunities by linking schools and community organizations reduces the age-related decline in moderate to vigorous physical activity in middle-school girls. Schools were randomly assigned to treatment conditions, resulting in 3 intervention and 3 control schools per site, for a total of 18 intervention and 18 control schools. All data reported in this article were collected prior to randomization.

\section{School Eligibility and Recruitment}

Public middle schools with a majority of students living in the surrounding community (ie, nonmagnet schools) were eligible to participate in TAAG. Additional school eligibility criteria included (1) enrollment of at least 90 8th-grade girls, (2) yearly withdrawal rates less than $28 \%$, (3) at least 1 semester of physical education required for each grade, and (4) willingness to sign a memorandum of understanding and to accept randomization assignment.

University-based field sites identified school districts and middle schools within driving distance (up to 100 miles in distance) and searched public access data sources for schools that met eligibility criteria. With the permission of the district, meetings to introduce TAAG were scheduled with principals. Recruitment continued until 6 schools per site (ie, 36 schools) were enrolled in the trial. ${ }^{13}$ Of the 68 schools that were contacted and invited to participate, 41 agreed and 36 were selected. Schools that did not agree to participate either did not respond to initial contacts or did not want to participate in a research trial. Schools selected were closer in distance to the field sites (between 4 and 104 miles) than those not selected. Across the 6 field sites, 19 urban and suburban school districts were represented. For the most part, TAAG schools represented the demographic and socioeconomic makeup of their district, with preference given to schools with greater racial/ethnic and socioeconomic diversity.

\section{Procedures}

Interviews with school principals, physical education and health education department heads, and leaders of school-based physical activity programs were conducted at each school to document instructional practices and policies that enhance and/or limit opportunities for students' physical activity. A unique instrument was created to obtain specific information from each respondent. All instruments and protocols were field-tested and revised prior to use. Representatives from each field site were trained and certified on data collection procedures prior to data collection. Each site obtained the appropriate Institutional Review Board approval. The first physical education department head interview was conducted in the fall of 2002; all other data were collected in the late spring of 2003.

Principal Interviews-Current physical activity policies were obtained through a 43-item, 30- to 45-minute structured interview with school principals or designees who were asked about physical education, health education, student exposure to physical activity promotions and/or events, school policies that support or constrain physical activity, transportation, 
structured and unstructured physical activity opportunities, and collaborations with community organizations that provide physical activity programs for adolescents.

\section{Physical Education and Health Education Department Head Interviews-}

Structured interviews were conducted with physical education department heads to capture instructional practices, barriers, and adequacy of equipment and facilities to implement the school's physical education curriculum. Items included school physical education requirements by grade level, average class size, resources and materials used to implement the curriculum, and barriers to teaching quality physical education at the school. The health education department head interview emphasized how many health education lessons each grade received on topics related to physical activity and/or physical fitness.

Physical Activity Programs Interviews-A 2-step process was required to obtain information on physical activity programs for girls. The person responsible for scheduling school facilities was asked to recall the physical activity programs offered throughout the current school year and the program leader or sponsor for each program. Subsequently, each sponsor was queried on the length of the program, frequency of the program (per week), number of minutes for each session, the grade levels involved in the program, and the approximate number of girls and boys, if applicable, in attendance. Girls-only and coed programs were surveyed because TAAG focused on girls' physical activity.

\section{Statistical Analyses}

Descriptive statistics (means, medians, and inter-quartile ranges) were calculated; mean and median values were similar, so mean values are reported in the text and tables. In most cases, results were similar across study sites. When there were substantial contrasts by site, these contrasts are reported. To determine schools with environments supportive of physical activity, 10 criteria (Table 2) were identified from documents from the CDC and Department of Health and Human Services, ${ }^{9}, 10$ including policies, training, and programs recommended by government agencies to promote physical activity. Schools were given 1 point for each criterion met. In addition, a school environmental physical activity support score was created using the sum of each of the 10 items for each school.

Univariate regression analysis was performed to identify factors that predicted a school with an environment supportive of physical activity. School demographics (school enrollment, percent free/reduced school lunch participation, and percent minority student enrollment) and school and district support for physical activity (ie, perceived school priority for physical education, perceived priority of physical education over coaching, perceived district support for physical education, perceived barriers for walking/biking to school, and school collaboration with community agencies) were evaluated. All data were analyzed using the Statistical Analysis System (SAS, Cary, NC) version 8.2.

\section{RESULTS}

Demographic information for the 36 middle schools is displayed in Table 1. School enrollment was between 613 and 1777 students, with an average size of 1022 students. The racial/ethnic makeup of the schools reflected the population diversity of the geographic locations at the field sites. Half of the schools had at least one third of students participating in the free or reduced lunch program. The percentage of students receiving free or reduced lunch ranged from $0 \%$ at an Arizona school to $91 \%$ at a Louisiana school. 


\section{School Policies and Instructional Practices}

Across 6th, 7th, and 8 th grades, $75 \%, 86 \%$, and $78 \%$ of schools, respectively, reported including information on physical activity and/or fitness topics in the health education curriculum. Approximately 7 health education lessons were taught at each grade level, although 4 of the 6 field sites had schools that provided no lessons on these topics. In contrast, 1 school covered the topic at least partially in 30 lessons.

Average yearly exposure to physical education class was approximately 110 hours in each grade. Schools in California had the highest exposure (156 hours per year), and the South Carolina schools had the lowest exposure (50 hours per year). Physical education was coeducational in all but 4 schools. For 3 schools, more than $10 \%$ of students were excused from enrolling in physical education. Two schools reported up to $25 \%$ of physical education classes shortened or canceled. Eight schools allowed free play in physical education class about once per month, 4 schools allowed free play 2-3 times per month, and 3 schools allowed free play at least 4 times per month.

Eighty-three percent of the schools (30 schools) offered interscholastic sports, and 69\% (25 schools) offered intramural sports. Two thirds had late buses (only 1 school in Louisiana), allowing students to remain on school grounds after school. While 50\% of schools allowed free play before school and 64\% allowed free play during lunch, only $25 \%$ ( 9 schools; 4 from Maryland) of schools reported that students used facilities for free play after school.

All schools but 1 allowed students to bicycle to school. An average of $21 \%$ of students either walked or biked regularly to school, although each site had at least 1 school in which only $5 \%$ of students walked or biked. At 1 school in Louisiana, $85 \%$ of students walked or biked to school. The most common barrier to walking or bicycling was traffic (cited by 30 schools [83\%]), followed by distance from home to school (26 schools [72\%]). Other barriers included no sidewalks or routes to school (47\%), weather (28\%), student safety concerns $(25 \%)$, and no place to secure bicycles $(11 \%)$. Three schools reported no barriers. Schools that reported no barriers had similar walking/biking patterns (22\%) as schools reporting barriers (18\%) (difference not significant).

\section{Barriers to Optimal Implementation of Physical Education}

Department heads in 20 of 36 schools identified the primary obstacles to implementing quality physical education as being that physical education was not a school priority and class sizes were inappropriate. Other major obstacles were lack of funding and lack of indoor facilities (19 schools [53\%]), with insufficient physical education staff development and physical education not a priority for students also listed by 17 schools. Approximately $30 \%$ ( 11 schools) identified lack of district support and lack of equipment as barriers.

\section{School Physical Activity Events and Programs}

Most schools had both physical activity events or campaigns and physical activity programs for girls (ie, either coed or girls only) in all 3 grades. On average, 24 ( $\sim \%$ of population) girls attended programs per school. Only 14 schools (all 6 in California) collaborated with groups external to the schools to provide programs.

\section{School Composite Environmental Support for Physical Activity}

Individual criterion and total scores to assess the schools' environmental support for physical activity are displayed in Table 2. On average, schools scored less than 7 points (6.7), with a range of 3-9. No school met all 10 criteria. Univariate regression analysis indicated that schools with a higher proportion of students using the free or reduced lunch program were associated with lower school environmental support score $(\mathrm{F}=4.51 ; \mathrm{p}=.041)$. Perceived value of physical 
education over coaching was associated with higher school environmental support score $(\mathrm{F}=$ $6.12 ; \mathrm{p}=.0186)$ and personal safety not a barrier for walking or bicycling to school $(\mathrm{F}=5.83$; $\mathrm{p}=.0213)$.

\section{DISCUSSION}

This report documents the policies, instructional practices, and barriers regarding physical activity for middle schools that are diverse in terms of geography, racial/ethnic makeup, and socioeconomic status. Although schools reported some policies and practices that indicated support for physical activity, unfavorable practices and barriers also were reported. For example, whereas most schools offered after-school physical activity programs for girls, only about 25 girls at each school (approximately less than 5\%), on average, attended the programs. This level of participation is similar to that reported by Powers et al for girls participating in extracurricular physical activity programs in San Diego-area middle schools. ${ }^{14}$ There were clearly barriers to participation, which likely included interest in the types of programs offered, transportation, and cost.

Favorable practices that support physical activity were noted. Overall, 10 out of the 36 schools (including all 6 of the California schools) required daily physical education. Daily physical education is recommended by national groups as a policy that increases children's physical activity. ${ }^{7}$ Almost two thirds of the schools had activity buses that allowed bused students to remain after school for programs. Intramural and interscholastic sports allowed girls with differing preferences and abilities to be involved in sports. All but 1 school allowed students to bike to school, only 4 schools had barriers to biking that were directly under their control (ie, no way to secure bikes), and 3 schools reported no barriers-all indicators of favorable practices. Free play outside of class was allowed at most schools. Although free play offers less potential for physical activity than structured programs, when school environments have physical improvements (eg, basketball courts) and allow students access to the environments, physical activity occurs. 15

Some schools reported practices that were unfavorable to physical activity. Free play, allowed once a month or more by almost half the physical education departments, does not provide students with meaningful opportunities to learn and practice physical skills. In addition, excusing students from physical education class and shortening or canceling physical education classes in favor of other instructional or school-related activities (eg, picture taking) occurred in over $7 \%$ of classes and as much as $25 \%$ of the time at some TAAG schools. This sends the message to students that physical education is not highly valued by the school.

At most schools, less than one quarter of students regularly walked or biked to school. This is similar to results of a national survey administered in 1999 , showing that $19.6 \%$ and $5.7 \%$ of secondary school-aged children walked or biked to school, respectively. ${ }^{16}$ Barriers reported by TAAG school principals were also consistent with those reported by parents of school-aged children. Long distances, traffic danger, adverse weather, and crime were cited as major barriers to walking or biking. ${ }^{16}$ The national data also indicated that when parents reported no barriers, children were more than 6 times likely to walk or bike to school than children whose parents reported at least 1 barrier. A study that evaluated urban form changes resulting from the California Safe Routes to School (SR2S) legislation indicated increased walking or bicycling travel for those students whose commute took them past SR2S construction projects. 17 Creating safe and accessible routes to school can be accomplished through planning of urban design features, involving parents and other adults in innovative activities, such as walking school buses and bike trains, and addressing traffic safety concerns. ${ }^{16}$ 
The 2000 School Health Policies and Programs Study ${ }^{18}$ provided limited information on physical education requirements at the state and national levels that can be used to compare to TAAG schools. Nationally, $25 \%$ of middle schools exempted students from physical education courses. ${ }^{19}$ In contrast, $8 \%$ of TAAG schools implemented policies that excused students from physical education. TAAG schools were comparable to national data regarding class size: $44 \%$ of TAAG middle schools had a maximal allowable class size of less than 30:1 compared with $42 \%$ nationally. Only $6 \%$ of middle schools required daily physical education compared to $28 \%$ of TAAG schools. However, when excluding the California schools that require daily physical education, only $10 \%$ of TAAG schools had daily physical education. TAAG schools were also more likely to offer intramural sports $(69 \%$ vs $49 \%)$ and provide access to school space for free play (78\% vs 37\%). ${ }^{19}$ Thus, this report offers a best-case scenario of schools.

There were no available studies that combined school policies and practices to obtain an environmental support score for physical activity. Tompkins et al ${ }^{11}$ used similar methodology to assess frequency of physical education and recess, access to facilities, and additional physical activity opportunities in West Virginia schools. However, they did not combine data to determine opportunities at the school level. ${ }^{11}$ In addition, no previous work has examined school-level demographic variables to assess school environmental support. This work found that participation in the free and reduced lunch program was negatively associated with the school environmental support for physical activity score. Although it is not surprising that schools with higher socioeconomic levels have greater opportunities for physical activity, no previous work has documented this association. Given that low-income adolescents report lower physical activity and less access to safe recreational facilities, ${ }^{20}$ schools serving these students should ensure that opportunities are available. Allowing free play after school hours is a policy that can be implemented without substantial increases in costs, as is encouraging teachers to sponsor after-school physical activity programs.

Four schools implemented single-gender physical education. Although the benefits of coeducational versus single-gender physical education are still being debated, ${ }^{21}$ McKenzie et al found that middle-school girls in coeducational physical education were more active than those in single-gender classes. ${ }^{22}$ They also found that girls-only classes spent more time in skill drills. In TAAG formative research, girls said that boys' negative attitudes toward girls' skill levels were major barriers to girls' participation in physical activity. ${ }^{23}$ If single-gender physical education provides additional opportunities for girls to learn skills necessary to competently engage in physical activity, this class format may be beneficial. However, school districts must also consider the implications of implementing title IX as well as the overall benefits of coeducational instruction, which may include enhanced physical activity for all students during class.

Results are limited to the schools recruited for TAAG. Only 6 geographic regions of the country were represented, although the 36 schools did represent a broad range of socioeconomic status and racial/ethnic diversity that was representative of schools in their respective districts. It is possible that schools more favorably disposed to physical activity and its promotion were more likely to volunteer for TAAG. The present environmental profile of schools may constitute a best-case scenario, at least for public, non-charter middle schools. For example, all TAAG schools required physical education (an eligibility criterion), compared nationally to schools in which $32 \%$ and $25 \%$ require physical education for 6 th and 8 th grades, respectively. ${ }^{19}$ While the results cannot be generalized to all middle schools in the nation, this research documents numerous barriers to physical activity school environments and suggests that even "best-case scenario" schools can be substantially improved.

The information can provide schools and school districts with methods to evaluate and compare their schools' ability to support, encourage, and promote physically active youth. The extent 
of the problem of physical inactivity and its associated comorbidities in youth is substantial, and schools have been asked to contribute to the solution. The methods developed to assess achievement of national recommendations can be modeled, and the results can be compared to TAAG schools.

In conclusion, this report provides information regarding the extent to which national recommendations for physical activity are being implemented in middle schools in diverse geographic regions of the country. Although results indicate that schools do have some policies and practices in place that support physical activity, unfavorable practices and barriers also exist. Schools will have to work with community partners, district officials, and local, state, and national representatives to provide environments that optimally support physical activity.

\section{Acknowledgements}

This work was funded by National Institutes of Health grants U01HL66845, U01HL66852, U01HL66853,

U01HL66855, U01HL66856, U01HL66857, and U01HL66858.

\section{References}

1. Hedley AA, Ogden CL, Johnson CL, Carroll MD, Curtin LR, Flegal KM. Prevalence of overweight and obesity among US children, adolescents, and adults, 1999-2002. JAMA 2004;291(23):28472850. [PubMed: 15199035]

2. Kimm SY, Glynn NW, Kriska AM, et al. Longitudinal changes in physical activity in a biracial cohort during adolescence. Med Sci Sports Exerc 2000;32(8):1445-1454. [PubMed: 10949011]

3. Freedman DS, Khan LK, Dietz WH, Srinivasan SR, Berenson GS. Relationship of childhood obesity to coronary heart disease risk factors in adulthood: the Bogalusa Heart Study. Pediatrics 2001;108(3): 712-718. [PubMed: 11533341]

4. Raitakari OT, Porkka KV, Taimela S, Telama R, Rasanen L, Viikari JS. Effects of persistent physical activity and inactivity on coronary risk factors in children and young adults. The Cardiovascular Risk in Young Finns Study. Am J Epidemiol 1994;140(3):195-205. [PubMed: 8030623]

5. Trudeau F, Laurencelle L, Shephard RJ. Tracking of physical activity from childhood to adulthood. Med Sci Sports Exerc 2004;36(11):1937-1943. [PubMed: 15514510]

6. Twisk JW, Kemper HC, van MW, Post GB. Tracking of risk factors for coronary heart disease over a 14-year period: a comparison between lifestyle and biologic risk factors with data from the Amsterdam Growth and Health Study. Am J Epidemiol 1997;145(10):888-898. [PubMed: 9149660]

7. Centers for Disease Control and Prevention. Guidelines for school and community programs to promote lifelong physical activity among young people. MMWR Morb Mortal Wkly Rep 1997;46:1-36. [PubMed: 9011775]

8. Stone EJ, McKenzie TL, Welk GJ, Booth ML. Effects of physical activity interventions in youth. Review and synthesis. Am J Prev Med 1998;15(4):298-315. [PubMed: 9838974]

9. Centers for Disease Control and Prevention. State-Level School Health Policies and Practices: A Stateby-State Summary from the School Health Policies and Programs Study 2000. Atlanta, Ga: US Department of Health and Human Services, Centers for Disease Control and Prevention, National Center for Chronic Disease Prevention and Health Promotion; 2001.

10. Promoting Better Health for Young People Through Physical Activity and Health. A Report to the President from the Secretary of Health and Human Services and the Secretary of Education. 2000. http://www.cdc.gov/healthyyouth/physicalactivity/promoting_health/

11. Tompkins N, Zizzi S, Zedosky L, Wright J, Vitullo E. School-based opportunities for physical activity in West Virginia public schools. Prev Med 2004;39:834-840. [PubMed: 15351553]

12. US Department of Health and Human Services. Physical Activity and Health: A Report of the Surgeon General. Atlanta, Ga: US Department of Health and Human Services, Centers for Disease Control and Prevention, National Center for Chronic Disease Prevention and Health Promotion; 1996.

13. Stevens J, Murray DM, Catellier DJ, et al. Design of the trial of activity in adolescent girls (TAAG). Contemp Clin Trials 2005;26(2):223-233. [PubMed: 15837442] 
14. Powers HS, Conway TL, McKenzie TL, Sallis JF, Marshall SJ. Participation in extracurricular physical activity programs at middle schools. Res Q Exerc Sport 2002;73(2):187-192. [PubMed: 12092893]

15. Sallis JF, Conway TL, Prochaska JJ, McKenzie TL, Marshall SJ, Brown M. The association of school environments with youth physical activity. Am J Public Health 2001;91(4):618-620. [PubMed: 11291375]

16. Centers for Disease Control and Prevention. Barriers to children walking and biking to schoolUnited States, 1999. MMWR Morb Mortal Wkly Rep 2002;51:701-704. [PubMed: 12206284]

17. Boarnet MG, Anderson CL, Day K, McMillan T, Alfonzo M. Evaluation of the California Safe Routes to School legislation: urban form changes and children's active transportation to school. Am J Prev Med 2005;28(2 suppl 2):134-140. [PubMed: 15694521]

18. Centers for Disease Control and Prevention. School Health Index for Physical Activity, Healthy Eating, and a Tobacco-Free Lifestyle: A Self-Assessment and Planning Guide. Middle School/High School Version. Atlanta, Ga: CDC; 2001.

19. Burgeson CR, Wechsler H, Brener ND, Young JC, Spain CG. Physical education and activity: results from the School Health Policies and Programs Study 2000. J Sch Health 2001;71(7):279-293. [PubMed: 11586871]

20. Romero AJ. Low-income neighborhood barriers and resources for adolescents' physical activity. J Adolesc Health 2005;36(3):253-259. [PubMed: 15737782]

21. Penney, D. Gender and Physical Education: Contemporary Issues and Future Directions. New York, NY: Routledge; 2002.

22. McKenzie TL, Prochaska JJ, Sallis JF, LaMaster KJ. Coeducational and single-sex physical education in middle schools: impact on physical activity. Res Q Exerc Sport 2004;75:446-449. [PubMed: 15673045]

23. Vu M, Murrie D, Gonzalez V, Jobe JB. Listening to girls and boys talk about girls' physical activity behaviors. Health Educ Behav 2006;33(1):81-96. [PubMed: 16397161] 
Table 1

School Demographics for the TAAG Field Sites; 6 Middle Schools per Field Site (N = 36 Middle Schools)

\begin{tabular}{|c|c|c|c|c|c|c|c|}
\hline & $\mathbf{A Z}$ & CA & MD & LA & MN & SC & All Sites \\
\hline $\begin{array}{l}\text { Average school } \\
\text { size (range) }\end{array}$ & $\begin{array}{c}821(613- \\
1033)\end{array}$ & $\begin{array}{c}1194(666- \\
1777)\end{array}$ & $\begin{array}{c}1005(812- \\
1463)\end{array}$ & $\begin{array}{c}977(777- \\
1470)\end{array}$ & $\begin{array}{c}1155(860- \\
1726)\end{array}$ & $\begin{array}{c}979(866- \\
1101)\end{array}$ & $\begin{array}{c}1022(613- \\
1777)\end{array}$ \\
\hline \multicolumn{8}{|l|}{ Race (\%, range) } \\
\hline White & $58(8-84)$ & $48(28-78)$ & $54(29-77)$ & $21(1-47)$ & $88(78-95)$ & $\begin{array}{c}54(26- \\
71)\end{array}$ & $54(1-95)$ \\
\hline African American & $2(1-4)$ & $11(2-22)$ & $28(14-55)$ & $\begin{array}{c}64(32- \\
99)\end{array}$ & $3(1-8)$ & $\begin{array}{c}39(22- \\
63)\end{array}$ & $25(1-99)$ \\
\hline Hispanic & $\begin{array}{c}35(10- \\
84)\end{array}$ & $31(11-53)$ & $11(1-29)$ & $10(1-34)$ & $2(1-4)$ & $4(0-7)$ & $15(0-84)$ \\
\hline Asian/ & $4(1-8)$ & $8(4-14)$ & $9(2-17)$ & $4(0-10)$ & $6(2-9)$ & $2(1-4)$ & $5(0-17)$ \\
\hline Pacific Islander & $1(0-3)$ & $1(0-1)$ & 0 & $1(0-1)$ & $1(1-2)$ & $1(0-5)$ & $1(0-5)$ \\
\hline American Indian & & & & & & & \\
\hline Other & 0 & $2.2(0-6)$ & 0 & 0 & 0 & 0 & $0.4(0-6)$ \\
\hline $\begin{array}{l}\text { Number of } \\
\text { schools with more } \\
\text { than } 33 \% \text { of } \\
\text { students with free } \\
\text { or reduced lunch }\end{array}$ & 2 & 4 & 3 & 6 & 0 & 3 & 18 \\
\hline
\end{tabular}




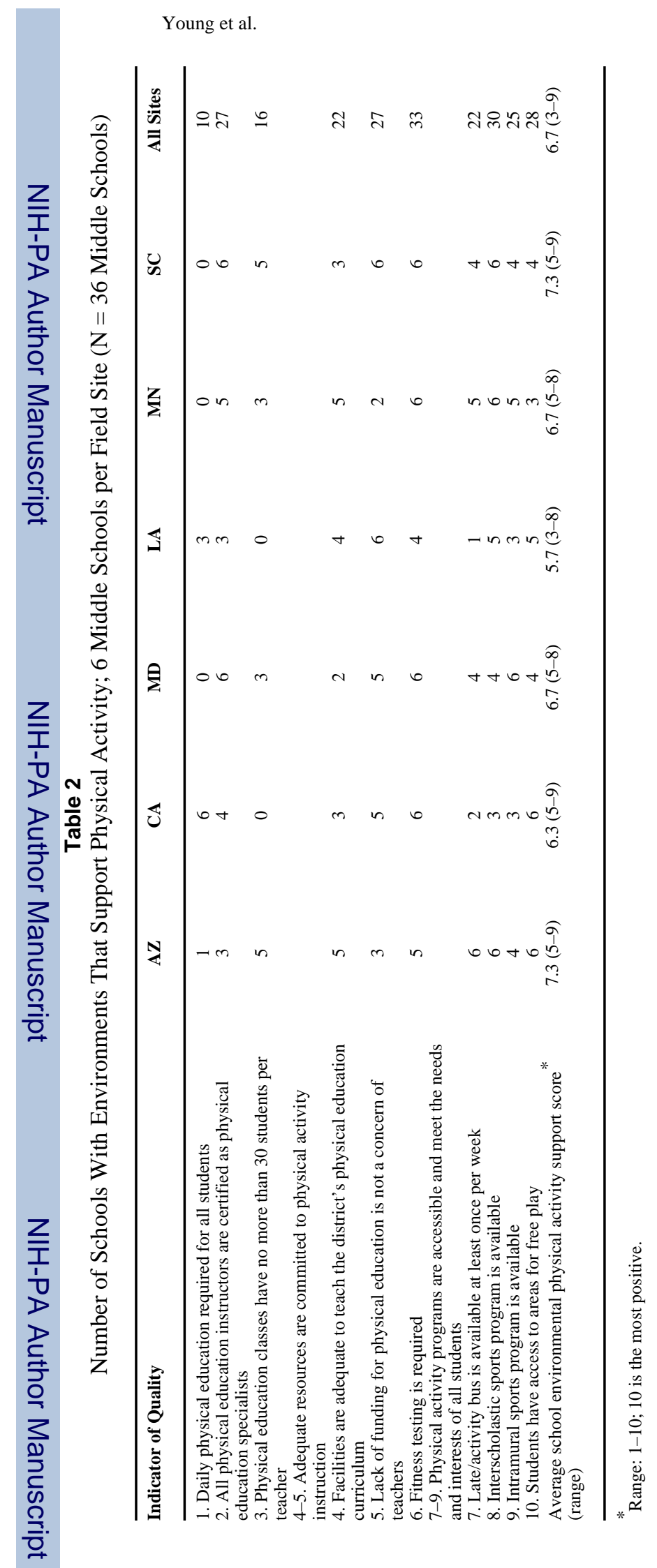

Page 11 